\title{
NEUROPSYCHOLOGICAL, NEUROIMAGE AND PSYCHIATRIC ASPECTS OF PRIMARY SJÖGREN'S SYNDROME
}

\author{
Gilberto N.O. Brito', Gloria R.B. Araujo', J. Angelo Papi
}

\begin{abstract}
We report a case of a 49-year-old woman diagnosed with primary Sjögrens Syndrome (pSS) who was submitted to extensive neuropsychobiological assessment. Examination revealed a Wechsler Adult Intelligence Scale-Revised (WAIS-R) Full Scale IQ of 97 with no Verbal/Performance IQ discrepancy and performance below estimated premorbid levels on arithmetic skills, visual tracking, naming and delayed paired associate learning/memory. CT scans of the brain were normal. However, there were subcortical hyperintensities on MRI and left parieto-temporal hypoperfusion on SPECT. Neuropsychological impairment is consistent with the pattern of neuroimage findings. We hypothesize that the pathophysiological mechanisms of pSS involve direct immune attack on neurons in addition to indirect effects through small-vessel angiopathy and thereby induce natural fracture lines in behavior according to location in the central nervous system.
\end{abstract}

KEY WORDS: Sjögren's syndrome, neuropsychology, neuropsychoimmunology, neuroimage, psychiatry, neuropsychobiology.

\begin{abstract}
Aspectos neuropsicológicos, psiquiátricos e de neuroimagem da síndrome de Sjögren primária
RESUMO - No presente estudo, relatamos o caso de uma mulher de 49 anos de idade com o diagnóstico de síndrome de Sjögren primária (pSS) submetida à extensa avaliação neuropsicobiológica. O exame revelou QI Global de 97 na Escala de Avaliação da Inteligência Adulta de Wechsler sem discrepância significativa entre os QIs Verbal e Performance, além de desempenho abaixo da estimativa do nível pré-mórbido na aritmética, atenção visual, nomeação e aprendizado/memória de pares de palavras. A tomografia computadorizada do cérebro revelou-se normal. Entretanto, a ressonância magnética mostrou hiperintensidades subcorticais e a tomografia por emissão única de fotons (SPECT) revelou hipo-perfusão parieto-temporal esquerda. 0 perfil do desempenho neuropsicológico é compatível com o padrão de achados da neuroimagem. Pode-se hipotetizar que os mecanismos fisiopatológicos da pSS envolvem ataque imune direto aos neurônios e efeitos indiretos via angiopatia de pequenos vasos, assim induzindo linhas naturais de fratura no comportamento de acordo com a localização no sistema nervoso central.
\end{abstract}

PALAVRAS-CHAVE: síndrome de Sjögren, neuropsicologia, neuropsicoimunologia, neuroimagem, psiquiatria, neuropsicobiologia.

In a recent review, Manoussakis, Talal and Moutsopoulos ${ }^{1}$ stated that the neurological manifestations of primary Sjögren syndrome (pSS) occur in about 10 to $20 \%$ of the cases mostly involving the cranial nerves and the peripheral nervous system (PNS). According to these investigators, neurological manifestations referred to the central nervous system (CNS) are considered controversial. However, the association between pSS and Parkinsonism ${ }^{2}$ and the mimicry of CNS lesions in pSS and multiple sclero- sis $^{3}$ have been reported. Furthermore, the prevalence of neuropsychiatric disorders with presumed CNS involvement in pSS has been determined to be in the range of 25 to $30 \%{ }^{4}$, which is consistent with preliminary and unpublished information obtained in a survey recently conducted with SS patients through the Brazilian SS Association (Lagrima-Brasil). Additionally, a neuroimage study reported that $81 \%$ of the pSS patients with neuropsychiatric involvement had abnormal SPECT perfusion patterns espe-

\footnotetext{
1Pesquisador Titular e Chefe, Laboratório de Neuropsicologia Clinica, Setor de Neurociências, Instituto Fernandes Figueira, FIOCRUZ, Rio de Janeiro RJ, Brasil, and Professor Adjunto Doutor, Universidade Federal Fluminense, Niterói RJ, Brasil; ${ }^{2}$ Psiquiatra Doutora do Serviço de Psicologia Médica e Saúde Mental, Hospital Universitário Clementino Fraga Filho, Rio de Janeiro; ${ }^{3}$ Professor Titular, Ambulatório de Programa Especial: Colagenoses, Serviço de Clinica Médica, Hospital Universitário Clementino Fraga Filho, Universidade Federal do Rio de Janeiro, Rio de Janeiro RJ, Brasil. Study supported by FUNPENE and Lagrima-Brasil. This paper was presented at the VII International Symposium on Sjögren's Syndrome held in Venice, Italy in December of 1999.
}

Received 5 July 2001, received in final form 3 September 2001. Accepted 20 September 2001. 
cially in the temporal lobes ${ }^{5}$. Lafitte $^{6}$ concluded that the CNS is affected in pSS mostly in the form of multifocal lesions of the brain and spinal cord probably related to small-vessel angiopathy. Such lesions may present clinically as an aseptic meningoencephalitis or as cognitive impairment. Although the current available information indicates that the CNS is clearly affected in pSS, there still is a paucity of data on the neurobehavioral and psychiatric aspects of pSS.

In the present study, we report a case of a 49year-old woman who was submitted to extensive neuropsychological, neuroimage and psychiatric assessment in the hope to shed light on current controversies in regards to the extent of CNS involvement in pSS.

\section{CASE}

At the time of data collection, the patient (SCO) was a 49-year-old woman on medical leave from her job as a budget analyst for the largest Brazilian TV network. SCO's developmental milestones were uneventful. Symptoms referred to her eyes (sandy feeling, itchiness and burning sensation), mouth (increase in frequency of dental caries) and joints (redness and pain, mostly in the wrists, elbows and ankles) first appeared when SCO was 25 years. At this time, she received a diagnosis of probable sarcoidosis and was medicated with colchicine and corticoids. Over the next ten years, SCO had frequent and intense crises of soreness in the eyes and joints which were abated by corticoids. After this time, the pain in the joints progressively diminished in intensity. However, the eye symptoms worsened and she began to feel dryness in her mouth, skin and hair. At 47 years of age, a clinical immunologist suspected of SS and referred her to an ophthalmologist. Since the Schirmer-1 and Rose-Bengal tests were positive on both eyes, she was further referred to a rheumatologist. A blood test for anti-nuclear antibodies was positive at the 1:40 dilution with a speckled pattern of immunofluorescence. However, other tests for the presence of autoantibodies, including anti-Ro/SSA, anti-La/SSB, anti-DNA, anti-SM, antiRNP, antineutrophil cytoplasmic and anti-cardiolipins (IgG and $\lg \mathrm{M})$, were all negative. Additionally, rheumatoid factor was undetectable. Furthermore, a salivary-gland scintigraphy showed poor fixation of the radionuclide and a stimulation test revealed no further functional activity of the salivary glands. These findings are characteristic of the sialoadenitis typically observed in pSS. Salivary gland histopathology was not conducted. Therefore, SCO fulfilled the Copenhagen criteria ${ }^{7}$ for pSS and, except for lack of salivary gland histopathology, she also fulfilled the European Community criteria ${ }^{8}$.

Interviewed by a psychiatrist in 1998, SCO presented with difficulties in sleeping, aggressiveness and "anxiousdepressive mood". Behavioral and psychiatric symptoms were further evaluated with instruments available in the ECDEU Assessment Manual9: the Symptom Checklist-90, the Brief Psychiatric Rating Scale, the Zung's Self-Rating Depression and Anxiety scales and the short form of the Beck Depression Inventory. Scoring procedures for these instruments were as described in the ECDEU Assessment Manual ${ }^{9}$. Moreover, interviews with family members and colleagues revealed that SCO was having dificulties in attention, naming, reading and memory, and her performance at work had deteriorated significantly. She was then referred to neuropsychological assessment.

Due to the dearth of knowledge on the neurobehavioral aspects of pSS, the neuropsychological examination was extensive and attempted to address a wide range of the major cognitive functions through a flexible-battery approach in the selection of instruments. The battery comprised neuropsychological tests discussed in Lezak ${ }^{10}$. Briefly, mental status was assessed with the Blessed Dementia

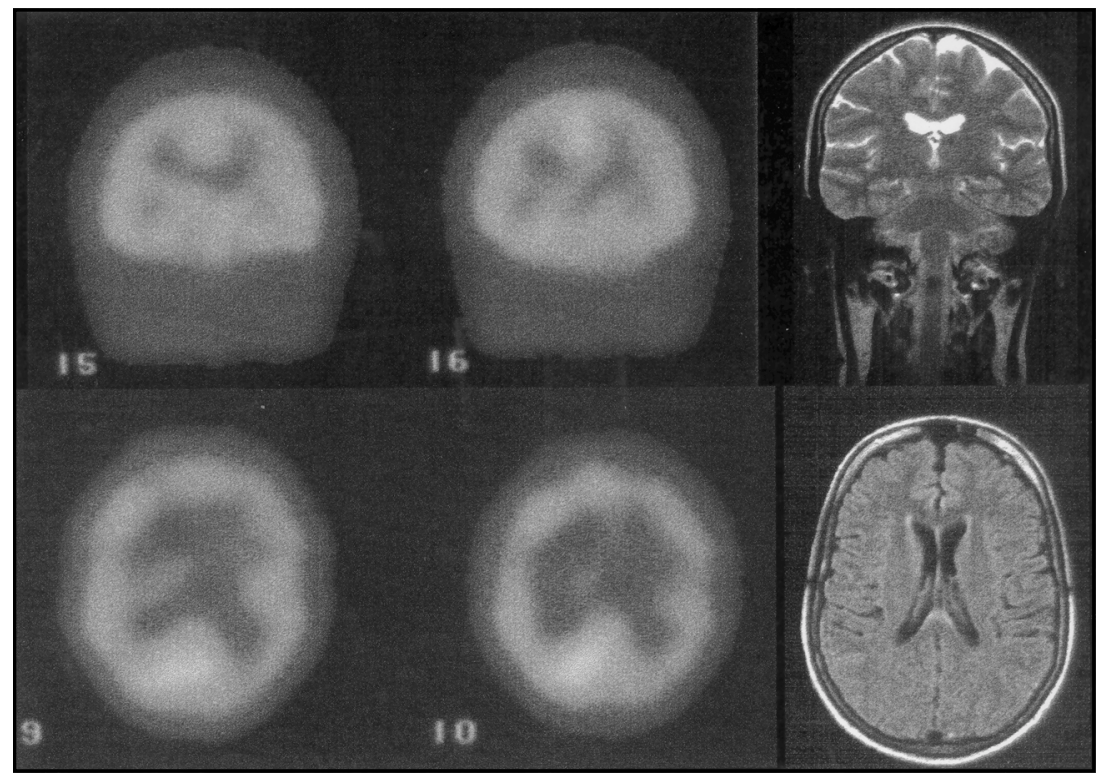

Fig 1. Left: Brain Tc-ECD-99m SPECT reveals a heterogeneous distribution of the tracer in both cerebral hemispheres and hypoperfusion in the left temporal and parietal areas. Right: Structural MRIs of the brain show hyperintense foci in subcortical regions of both hemispheres which do not impregnate with gadolinium. 
Rating Scale, the Mini-Mental Status Examination and the Mattis Dementia Rating Scale. A Meta-Cognition Rating Scale, a modified Hachinski Ischemic Score ${ }^{11}$ and the Edinburgh Handedness Inventory ${ }^{12}$ were also included in the battery. Intellectual ability was examined with the WAIS-R and the Raven's Standard Matrices while academic achievement was assessed with the Wide Range Achievement Test (WRAT3). Instruments used to assess orientation and attention included part A of the Trail Making Test, the Embedded Figures, Right-Left Discrimination and Finger Localization. Visual acuity was evaluated with the Snellen chart and tactile functions with the Face-Hand Test, skin writing and stereognosis. The Boston naming, word fluency (FAS and Animal) and the Token tests were used for the assessment of verbal functions. Verbal and nonverbal memory were evaluated with the Buschke's Selective Reminding Test, Fuld's Object-Memory Test, the Wechsler Memory Scale, Warrington's Recognition Memory Test, the Benton Visual Retention Test, and the Rey-Osterreith Complex Figure Test. Executive functions and motor performance were assessed with the Wisconsin Card Sorting Test, part B of the Trail Making Test, finger tapping and the Purdue Pegboard. SCO was on hydroxycloroquine, benzodiazepines and estrogen replacement therapy during neuropsychological examination.

CT scans of the head were collected with a Elscint 2400 scanner according to standard procedures. Brain MRI was conducted with a 0.5 Tesla Phillips Gyroscan scanner following standard procedures, including the IV administration of paramagnetic contrast (Gadolinium). Procedures for the SPECT included the use of technetium-99m-ECD which was prepared from a commercially available kit according to standard procedures. The scanner was a dual head gamma-camera Elscint Helix HR model. Following procedures previously described $^{5}$, a normal finding of TC$99 \mathrm{~m}-\mathrm{ECD}$ brain imaging consisted of homogeneous rCBF in the gray matter of the cerebral cortex and basal ganglia/thalamus without focal hypoperfusion or visible asymmetry. Otherwise, the brain SPECT result was deemed abnormal.

The results from the behavioral and psychiatric assessment with the Symptom Checklist-90, the Brief Psychiatric Rating Scale, Zung's Self-Rating Depression and Anxiety scales and the short form of the Beck Depression Inventory revealed the presence of mild anxiety and depression. The Hachinski Ischemic Score and visual acuity were normal and the Edinburgh Handedness Inventory showed that SCO is predominantly right-handed (laterality quotient $=+80$ ).

Information about SCO's educational and employment records allows us to estimate her overall premorbid neuropsychological functioning at a level 1.0 to 1.5 s.d. above the population mean. Therefore, for the purposes of the present report, the standard cutoff criterion score was set at 1.0 s.d., in lieu of the conventional 2.0 s.d., below the normative mean for the determination of impairment in neuropsychological performance. It should be emphasized,
Table 1. Summary of the results from the neuropsychological assessment of the patient.

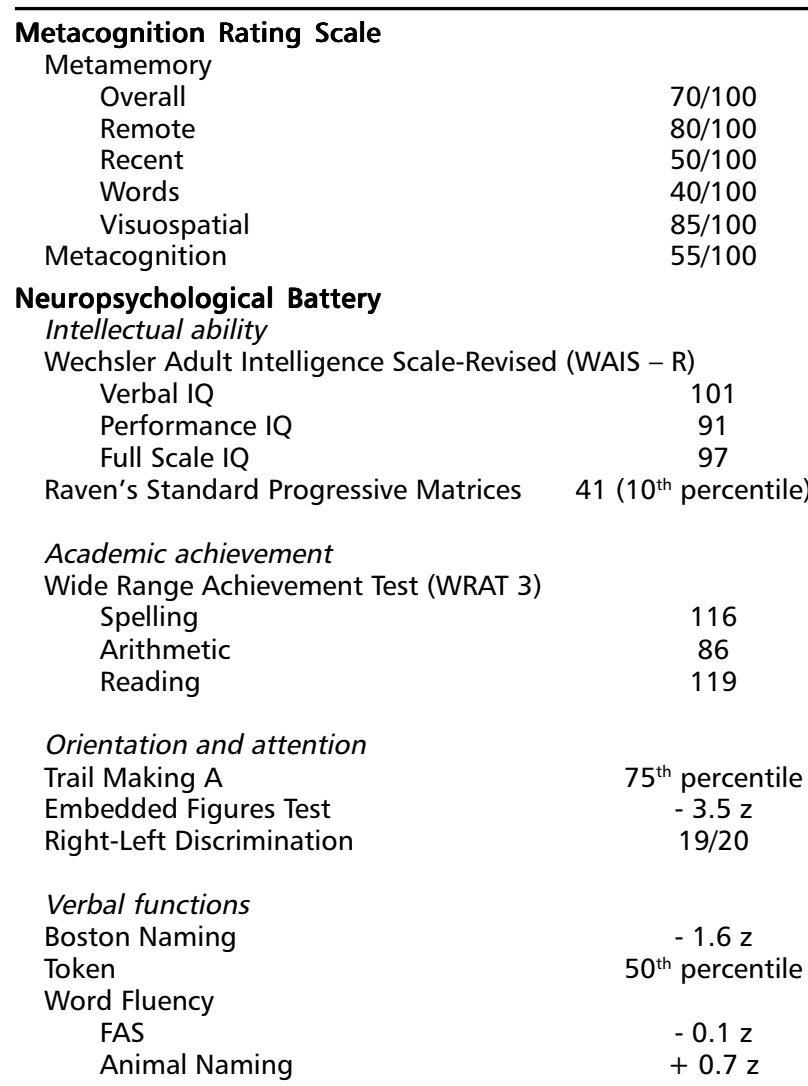

Construction

Benton Visual Retention Test - Adm C (error score) 0

Rey-Osterreith Complex Figure-Copy $+0.6 z$

Memory Functions

Verbal memory

Wechsler Memory Scale

Logical Memory

Immediate $\quad-0.7 \mathrm{z}$

Delay $\quad-0.4 z$

Associate Learning

Immediate $\quad-1.0 z$

Delay $\quad-2.8 \mathrm{z}$

Recognition Memory Test-Words $\quad+1.2 z$

Nonverbal memory

Benton Visual Retention Test - Adm A (error score)- $0.5 \mathrm{z}$

Rey-Osterrith Complex Figure - delay $\quad-0.3 \mathrm{z}$

Recognition Memory Test - faces $+0.7 \mathrm{z}$

Executive Functions and motor performance Wisconsin

$\begin{array}{lc}\text { Categories } & +1.8 \mathrm{z} \\ \text { Perseverative Errors } & +0.3 \mathrm{z} \\ \text { Maintain Set } & -0.8 \mathrm{z} \\ \text { ail Making B } & 75^{\text {th }} \text { percentile } \\ \text { Right hand } & \\ \text { Left hand } & -0.5 \mathrm{z} \\ \text { Purdue Pegboard } & -0.3 \mathrm{z} \\ \text { Right hand } & \\ \text { Left hand } & -0.8 \mathrm{z} \\ \text { Both hands } & -0.5 \mathrm{z} \\ \text { Assembly } & -0.7 \mathrm{z} \\ \end{array}$

$Z$, standardized score; $+/$, sign refers to better $(+)$ or worse (-) performance relative to the normative data for the test. 
however, that the setting of the cutoff criterion at 1.0 s.d. below the mean signifies that SCO's performance would be considered abnormal only if it reached a level about 2.0 s.d. below her estimated overall premorbid functioning level.

Table 1 summarizes the results from the neuropsychological assessment. The data (not shown) demonstrate that SCO had a normal mental status examination profile. As indicated in the table, the meta-assessment of cognitive functions revealed that SCO estimated her memory for words, recent memory and overall cognition at a much lower level than her visuospatial, remote and overall memory. Furthermore, the results from the neuropsychological examination demonstrated that SCO had verbal, performance and full scale IQs within the normal range and performed most of the neurobehavioral assessment instruments above the $1.0 \mathrm{s.d}$. below-the-mean criterion cutoff score set for the current study. Her performance was below criterion on the Raven's Matrices, arithmetic subtest of the WRAT3, Embedded Figures Test, Boston Naming Test and the delayed form of the Associate Learning subtest of the Wechsler Memory Scale.

As demonstrated in Figure 1 (left-hand side), the SPECT performed on the patient showed a pattern of hypoperfusion in the left temporal and parietal areas. MRI scans, also shown in Figure 1 (right-hand side), demonstrated hyperintense foci in subcortical regions of both hemispheres which probably represent gliotic changes secondary to small-vessel angiopathy.

\section{DISCUSSION}

The results from this study revealed neurobehavioral impairment and neuroimage alterations in a pSS patient submitted to extensive behavioral, psychiatric, neuropsychological and neuroimage examinations. We hypothetize that the pathophysiological mechanisms related to the interface of brain and the immune system affect the CNS in a nonspecific manner, both directly on neurons and indirectly through the cerebral blood vessels, and thereby induce natural fracture lines in behavior. These natural fracture lines in behavior obviously depend on the location of the combined direct and indirect immune attacks to the CNS. This hypothetical view is consistent with the finding of anti-neuronal antibodies in the postmortem brain of a pSS patient ${ }^{13}$ and with formulations on antineuronal antibody-mediated neuropsychiatric disorders in children ${ }^{14}$. The profile of the neuropsychological results obtained with SCO is in accord with the above hypothesis to the extent that it shows impairment in some, but not all, neuropsychological areas. Part of the neuropsychological impairment shown by SCO certainly depends upon brain mechanisms shown to be dysfunctional on SPECT. Except for the presence of antinuclear antibodies, the measurements of a broad array of antigen specific autoantibodies in the serum of SCO were unrevealing. Further to this point, negative findings in the measurement of autoantibodies in the serum have been reported in up to $30 \%$ of pSS patients ${ }^{15}$. Technical problems in immunologic assays certainly hinder the interpretation of clinical-immunologic correlations ${ }^{16}$. Further research, however, is sorely needed to firmly test the hypothesis that a direct immune attack on neurons in the CNS constitutes part of the pathophysiological mechanisms in pSS.

\section{REFERENCES}

1. Manoussakis MN, Talal N, Moutsopoulos HM. Sjögren's syndrome In Rose NR, MacKay IR, (eds). The autoimmune diseases. 3.Ed. New York: Academic Press; 1998: 381-404.

2. Walker RH, Spiera H, Brin MF, Olanow CW. Parkinsonism associated with Sjögren's syndrome: three cases and a review of the literature. Mov Disord 1999;14:262-268.

3. Alexander EL, Malinow K, Lejewski JE, Jerdan MS, Provost TT, Alexander GE. Primary Sjögren's syndrome with central nervous system disease mimicking multiple sclerosis. Ann Intern Med 1986;104:323-330.

4. Hietaharju A, Yli-Kerttula U, Häkkinen V, Frey H. Nervous system manifestations in Sjögren's syndrome. Acta Neurol Scand 1990;81:144-152.

5. Kao C-H, Yung-Jen H, Lan J-L, ChangLai S-P, Chieng P-U. Regional cerebral blood flow and glucose metabolism in Sjögren's syndrome. J Nucl Med 1998;39:1354-1356.

6. Lafitte C. Manifestations neurologiques du syndrome de GougerotSjögren primitif. Rev Neurol 1998;154:658-673.

7. Manthorpe R, Oxholm P, Prause JU. The Copenhagen criteria for Sjögren's syndrome. Scand J Rheumatol 1986;61(Suppl):19-21.

8. Vitali C, Bombardieri S, Moutsopoulos H. Preliminary criteria for the classification of Sjögren's syndrome: results of a prospective concerted action supported by the European Community. Arthritis Rheum 1993;36:340-347.

9. Guy W. ECDEU assessment manual for psychopharmacology. Rockville: US Department of Health, Education and Welfare; 1976.

10. Lezak MD. Neuropsychological assessment. 3.Ed. New York: Oxford Univ Press, 1995.

11. Rosen WG, Terry RD, Fuld PA, Katzman R, Peck A. Pathological verification of ischemic score in differentiation of dementias. Ann Neurol 1980;7:486-488.

12. Brito GNO, Brito LSO, Paumgartten FJR, Lins MFC. Lateral preferences in Brazilian adults: an analysis with the Edinburgh inventory. Cortex 1989;25:403-416

13. Rood MJ, Verschuuren JJGM, van Duinen SG, et al. CNS involvement in primary Sjögren's syndrome: a case with a clue for the pathogenesis. J Neurol 2000;247:63-64.

14. Swedo SE, Leonard HL, Kiessling LS. Speculations on antineuronal antibody-mediated neuropsychiatric disorders of childhood. Pediatrics 1994;93:323-326.

15. Montanaro A. Differential diagnosis of allergic disease: masqueraders of allergy: Sjögren's syndrome. Immunol Allergy Clin N Am 1996;16:1-15.

16. Pourmand N, Wahren-Herlenius M, Gunnarsson I, et al. Ro/SSA and $\mathrm{La} / \mathrm{SSB}$ specific IgA autoantibodies in serum of patients with Sjögren's syndrome and systemic lupus erythematosus. Ann Rheum Dis 1999;58:623-629. 